\title{
RENEWABLE ENERGY SYSTEM PERFORMANCE ANALYSIS WITH M-PSO POWER STABILIZING CONTROLLED CONVERTER
}

\author{
VIPUL PANDEY ${ }^{1}$, DR. RAJEEV ARYA ${ }^{2} \&$ SHRAVAN VISHWAKARMA ${ }^{3}$ \\ ${ }^{I}$ M. Tech Scholar, Truba Institute of Engineering and Information Technology, India \\ ${ }^{2}$ Director, Truba Institute of Engineering and Information Technology, India \\ ${ }^{3}$ Professor, Truba Institute of Engineering and Information Technology, India
}

Sustainable energy is the main driver of all applications of renewable energy sources. The main objective of the system is to be studied for integration with the solar and wind energy system also to obtain energy efficiency. The fuel system would be connected in parallel to the DC voltage output of the solar/wind hybrid system. Improvement in the reactive power output from the system by the inverter control by a designed hybrid system that can compensate for the reactive power requirement when required. The final hybrid system with fuel cell integration was studied for the total harmonic distortion in the voltage and current waveform and output active reactive powers. The distortion level in the voltage waveform was found to be $0.19 \%$ and that in the current waveform was $0.35 \%$. The final results showed better performance in terms of quality as compared to the basic swarm optimizing control.
\end{abstract}

KEYWORDS: Hybrid System, PV System, Fuel Cell, EC

Received: Oct 06, 2020; Accepted: Oct 26, 2020; Published: Nov 28, 2020; Paper Id.: IJMPERDOCT202069

\section{INTRODUCTION}

Sustainable energy is the main driver of all applications of renewable energy sources. The energy supply from renewable energy sources naturally fluctuates depending on the availability of the energy source. The availability of energy sources is largely unpredictable (eg wind, solar, etc.). Therefore, it is important to have other more predictable energy sources to ensure the availability of energy during times of low supply of energy from renewable sources. In times of excess energy, it is advantageous to store energy and make it available in times of low energy production and high energy demand. An efficient, high-density way to store energy is to produce fuel to store excess energy.

Integrating wind power and other large-scale renewable energy sources requires the development of an adequate grid infrastructure to cope with the variability of generation and load conditions. In times of high winds, excess energy from wind farms must be stored or diverted to other loads so that valuable energy is not wasted. Integrating systems based on solid oxide electrolysis cells (SOEC) and solid oxide fuel cells (SOFCs) on a large scale is an attractive solution to address excess energy and pitfalls.

Power electronics converters as interfaces between renewable energy sources, storage elements, power grid and customers have become increasingly important for power control and cost savings, energy and system reliability. The integration of electronic power converters as an interface for fuel cell (FC) and electrolytic cell (EC) based systems in the network leads to new and difficult problems in relation to cell dynamics slow and transient behavior. Therefore, hybrid generation systems are needed to achieve a rapid transient response. Additional energy storage elements such 
as batteries and super capacitor batteries are expected to be a critical component in increasing the dynamic performance of the system. Efficient power management and control of the system current flow into the various system components is a crucial point for system performance.

\section{LITERATURE REVIEW}

F. Paterakis et al. [1] a conventional 3-stage PWM inverter and a cascaded multilevel inverter, both rated at $230 \mathrm{~V}$ and $3 \mathrm{~kW}$ rms, are analyzed using the switching function. The PWM signal for the 3-level inverter is derived by applying the technique of the switching function to the principle of surface equality. For multilevel inverters in cascade, the switching function technique is initially applied to each $\mathrm{H}$ bridge and then added to derive the overall switching function for the multilevel inverter output.

Himadry Shekhar Das et al. [2] In this study, a $26 \mathrm{~kW}$ autonomous energy system based on proton exchange membrane fuel cells (PEMFCs) was developed with MATLAB / Simulink ${ }^{\circledR}$. The PEMFC stack is modeled on the basis of mathematical equations and implemented using Simulink blocks. Similarly, power converters are also modeled using Simulink block sets. The PEMFC output DC voltage is boosted using a boost DC-DC converter and then sent to a PWM inverter. The DC-DC boost converter regulator is a PI-based single-circuit voltage regulator.

AlirezaAskarzadeh et al. [3] Hybrid energy systems have attracted considerable attention to meet the electricity needs of autonomous areas. Among the different configurations, diesel photovoltaic (PV / Diesel) power generation systems are among the most promising for their good performance. This article focuses on the optimal sizing of a PV / Diesel power generation system using the Harmony Search (HS) algorithm.

Fabrizio Sossan et al. [4] In the paper, a comparison of the storage capacity per unit of investment cost is made taking into account the selected TCLs and two grid-connected battery storage systems (a $720 \mathrm{kVA} / 500 \mathrm{kWh}$ lithium-ion unit and is implemented a vanadium flow redox of $15 \mathrm{kVA} / 120 \mathrm{kWh}$ ). A method has been developed to quantify the equivalent storage capacity inherent in the operation of regulated thermostatic loads (TCL).

AliDaşdemir et al. [5] This article describes the effects of air gap on insulation thickness and life cycle costs of steel pipes of different diameters. The results show that the lowest optimal insulation thickness for natural gas and XPS insulation material was found in all conditions.

Huifeng Zhang et al. [6] In this work, the optimal model of the short-term hydrothermal system is extended to the optimal short-term planning of the economic emissions of hydrothermal systems, taking into account the integrated intermittent energy resources (SHOSEE-IIER). In order to adequately solve the SHOSEE-IIER problem, a differential cultural development based on different dignified and dignified objectives (GD-MOCDE) is proposed to improve the optimal efficiency of SHOSEE-IIER in combination with three facilities of Improve research capacity of differential expansion in the shortest path.

\section{OBJECTIVE}

The work proposes to attain following key objectives from the research:

- Designing of a grid integrated fuel energy system at for driving local loads for improving its reliability and efficiency. 
- Designing an inverter control comprising optimization algorithm for multiple electrical parameters at the load end that attains lower distortion level in the voltage as well as current waveforms.

- The system is to be studied for integration with the solar and wind energy system also to obtain the energy efficiency. The fuel system would be connected in parallel to the DC voltage output of the solar/wind hybrid system.

- Improvement in the reactive power output from the system by the inverter control by designed hybrid system that can compensate the reactive power requirement when required.

- This project should attain the hybrid solar/wind/fuel system with proposed controller to improve the output parameters.

\section{METHODOLOGY}

The PEMFC is an electrochemical device which allows the electric energy conversion of the chemical energy contained in a reaction between a fuel, the hydrogen, and an oxidizer, the oxygen. A bias voltage is applied across the electrochemical cell in order to induce electrochemical reactions at both electrodes. Water is introduced at the anode and dissociated into oxygen, protons, and electrons. The protons are driven by an electric field through the PEM to the cathode where they combine with the electrons arriving from the external circuit to form hydrogen gas.

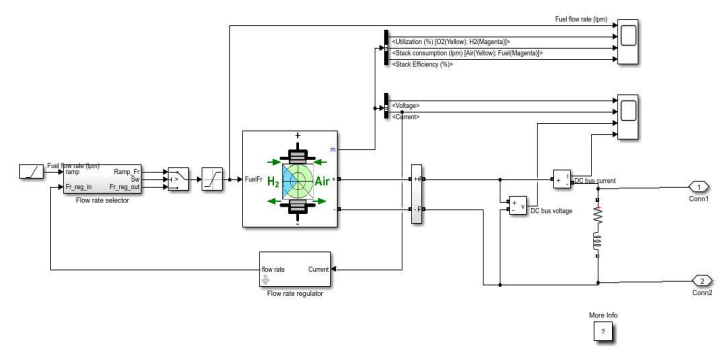

Figure 1: MATLAB/SIMULINK model of fuel system

Fuel cells are compact, low-noise energy generators that use hydrogen and oxygen to generate electricity. The transport sector is the most important potential market for fuel cells and car manufacturers invest heavily in research and development. However, energy production is seen as a market in which fuel cells can be marketed much faster. Fuel cells can achieve high efficiency (35\%-60\%) compared to conventional technologies. The figure shows the approach that has been followed to integrate the system with solar/wind energy system.

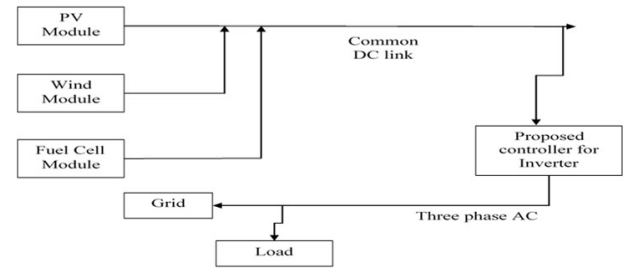

Figure 2: Connection approach foe hybrid solar/wind/fuel cell system

The solar/wind/fuel energy system was configured were configured to be connected in parallel having common voltage. 


\section{A. Boost Converter Designing}

The Boost Converter block represents a converter that steps up DC voltage as driven by an attached controller and gatesignal generator. Boost converters are also known as step-up voltage regulators because they increase voltage magnitude.

The Boost Converter block allows you to model an asynchronous converter with one switching device or a synchronous converter with two switching devices like GTO — Gate turn-off Thyristor, IGBT, MOSFET and Thyristors.

The Boost Converter block allows you to model an asynchronous converter with one switching device or a synchronous converter with two switching devices like GTO — Gate turn-off Thyristor, IGBT, MOSFET and Thyristors. In our work we have used a boost converter that is regulating the DC link voltage and stabilizing it for long run. The figure shows the DC voltage output from the system after using the DC-DC boost converter. IT was found to be improved to approximately 400 volts after boost conversion. This improves the voltage input to the inverter for DC/AC conversion utilizing metaheuristic approach for quality enhancement controller

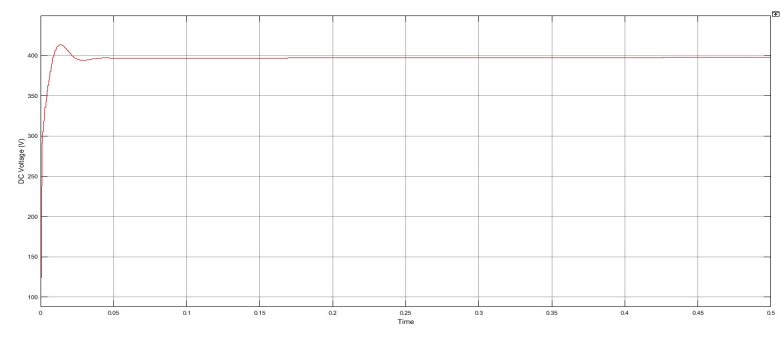

Figure 3: Common DC link voltage for all the energy resources

Metaheuristic M-PSO Power Stabilizing Controlled converter designing

The inverter control designing has been done so as to improve the system parameters. The designing has been done in $\mathrm{dq} 0$ reference frame to ease the study of the elemental parts and their respective changes. The system continuously keeps a check on the variable parameters using the PSO algorithm and updates as per the requirement.

Particle swarm optimization PSO is a novel swarm optimization algorithm that is firstly proposed by Kennedy as an evolutionary algorithm based on behavior of birds. PSO uses a set of particles that each one suggests a solution to the optimization problem [10]. It is based on the success of all particles that emulates a population where the position of each particle depends to the agent position to detect the best solution $\mathrm{P}_{\text {best }}$ by using current particles in the population $\mathrm{G}$. The position of any particle xi is adjusted by

$$
x_{i}^{k=1}=x_{i}^{k}+v_{i}
$$

where the velocity component vi represents the step size and is calculated by:

$$
v_{i}^{k}=w v_{i}^{k}+c_{1} r_{1}\left(P_{b^{2} t_{i}}-x_{i}^{k}\right)+c_{2} r_{2}\left(G-x_{i}^{k}\right)
$$

where $\mathrm{x}$ is the inertial weight, $\mathrm{c}_{1}$ and $\mathrm{c}_{2}$ are the acceleration coefficients, $\mathrm{r}_{1}$ and $\mathrm{r}_{2}$ are random values that belong to the interval of $[0,1]$, $\mathrm{P}_{\text {best_i }}$ is the best position of particle $\mathrm{i}$, and $\mathrm{G}$ is the best position in the entire population.

Similarly, the initial velocity values are defined randomly. The fitness value of each particle is evaluated in the second step where the fitness evaluation is leaded to provide candidate solution to the objective function. The individual and global best fitness values are determined in the third step where $p_{\text {best_i }}$ and $g_{\text {best }}$ are respectively determined. 


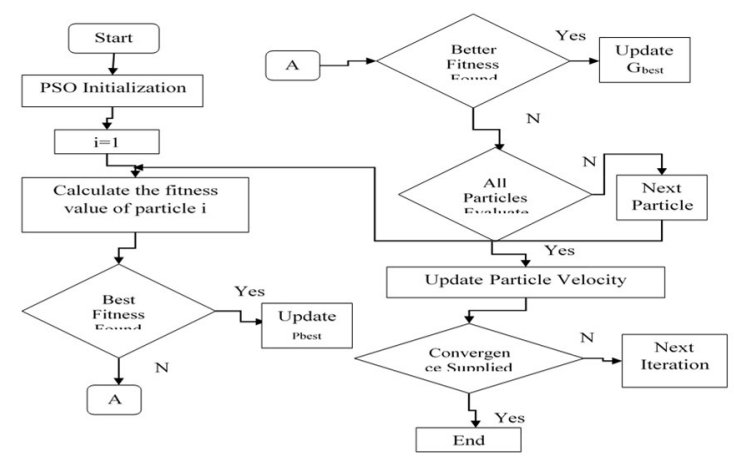

Figure 4: PSO- controller Technique implemented in MATLAB/SIMULINK

Then the positions are updated and replaced with better fitness values if they are found. The velocity and position of each particle are updated in the fourth step The last step of the flowchart checks the convergence criterion. If the criterion is met, the process is finished. Otherwise, the iteration number is increased and procedure returns to step 2.

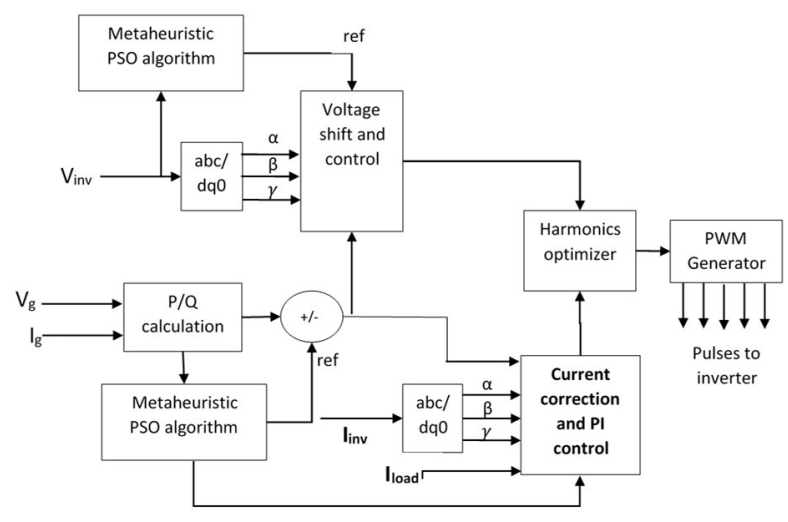

Figure 5: multi objective adaptive constraints approach for quality enhancement controller

The controller provides pulses to the inverter which is a three leg 6 pulse inverter. The controller takes grid parameters, load parameters and inverter output parameters as inputs. The active power and reactive power requirement has been checked and is meant to be improved as per the changes. The current reference control developed by the metaheuristic approach plays a crucial role in regulating the reactive power by adjusting phase as well as load requirement by adjusting the gain parameter of the PI control. The harmonic correction is done before the signal is sent to the PWM generator for pulse generation. This multi objective adaptive constraints approach for quality enhancement controller is meant to work and update at each point of the system variation to prove a better pulse so as to yield and enhanced output parameters.

Table1: PV module Parameters

\begin{tabular}{|l|c|}
\hline \multicolumn{1}{|c|}{ Model } & 1Soltech 1STH \\
\hline Maximum Power & 213.5 Watts \\
\hline Number of parallel strings & 40 \\
\hline Number series modules & 10 \\
\hline Open circuit voltage & 36.3 Volts \\
\hline Shot circuit current & $7.84 \mathrm{Ampere}$ \\
\hline Irradiation & $1000 \mathrm{wb} / \mathrm{m}^{2}$ \\
\hline Temperature & $30^{\circ} \mathrm{C}$ \\
\hline
\end{tabular}




\section{B. Wind Energy Integration with Proposed Controller}

Wind energy is also freely available in environment, pollution free source of energy. The performance of the output power generation of wind energy system various according to the wind potential of design location. The condition for feasible solution and techno-economic wind energy system is the selection of higher wind energy potential geographical location is necessary [6]. The feasible and cost effective model of wind system to compare, performance of different wind machines at various locations are investigated regarding average velocity and the turbine machine characteristics [6].

\section{Generator}

The energy in the wind turns two or three Propeller like blades around a rotor. The rotor is connected to the main shaft, which spins a generator to create electricity. Thus generator converts mechanical energy of wind turbine rotor into electrical energy

Model of wind turbine with PMSG Wind turbines cannot fully capture wind energy. The components of wind turbine have been modeled by the following equations.

Output aerodynamic power of the wind-turbine is expressed as:

$$
P_{\text {Turbine }}=\frac{1}{2} \rho A C_{p}(\lambda, \beta) v^{3} \mathrm{Eq}(1)
$$

where, $\rho$ is the air density (typically $1.225 \mathrm{~kg} / \mathrm{m} 3$ ), $A$ is the area swept by the rotor blades (in $\mathrm{m} 2$ ), $C P$ is the coefficient of power conversion and $v$ is the wind speed (in $\mathrm{m} / \mathrm{s}$ ).

The tip-speed ratio is defined as:

$$
\lambda=\frac{\omega_{m} R}{v} \operatorname{Eq}(2)
$$

where $\omega_{m}$ and $R$ are the rotor angular velocity (in $\mathrm{rad} / \mathrm{sec}$ ) and rotor radium (in m), respectively.

The wind turbine mechanical torque output $m T$ given as:

$T_{m}=\frac{1}{2} \rho A C_{p}(\lambda, \beta) v^{3} \frac{1}{\omega_{m}} \mathrm{Eq}(3)$

The power coefficient is a nonlinear function of the tipspeed ratio $\lambda$ and the blade pitch angle $\beta$ (in degrees).

Then Power output is given by

$P_{\text {Turbine }}=\frac{1}{2} \rho A C_{p_{\text {max }}} v^{3} \mathrm{Eq}(4)$

A generic equation is used to model the power coefficient $C_{P}$ based on the modeling turbine characteristics described in [2], [7-9] and [11] as:

$C_{p}=\frac{1}{2}\left(\frac{116}{\lambda_{i}}-0.4 \beta-5\right) e^{-\left(\frac{21}{\lambda_{i}}\right)} \operatorname{Eq}(5)$

For each wind speed, there exists a specific point in the wind generator power characteristic, MPPT, where the output power is maximized. Thus, the control of the WECS load results in a variable-speed operation of the turbine rotor, so the maximum power is extracted continuously from the wind. 


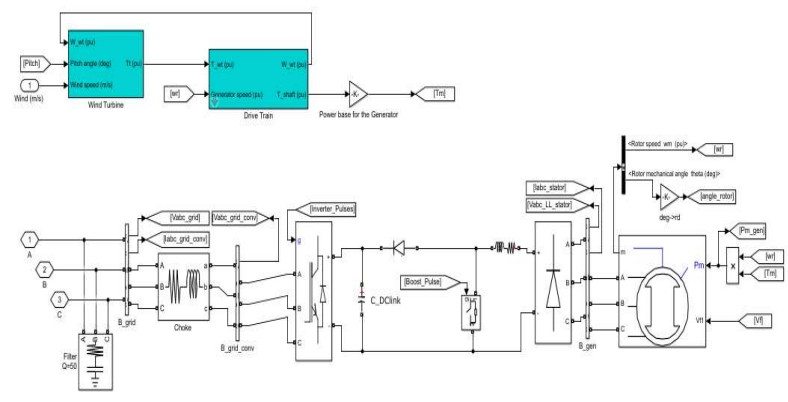

Figure 6: modeled Wind system

This mechanism uses the variable torque output $\mathrm{w}_{\mathrm{m}}$ and tries to optimize the output current and voltage waveform to its maximum value.

Table 2 :Wind energy system parameters

\begin{tabular}{|l|c|}
\hline \multicolumn{1}{|c|}{ Wind speed } & $\mathbf{1 5} \mathbf{~ m} / \mathbf{s e c}$ \\
\hline Number of wind turbines & 80 \\
\hline Nominal power & $1.5 \mathrm{KW}$ \\
\hline Frequency & $50 \mathrm{hertz}$ \\
\hline Line to line voltage & $410 \mathrm{~V}$ \\
\hline Friction factor & 0.01 \\
\hline Number of poles & 1 \\
\hline Inertia constant & 0.62 \\
\hline
\end{tabular}

\section{RESULTS}

A Hybrid Power System (HPS) utilizes two or more energy sources, power converters and/or storage devices. The main purpose of HPS is to combine multiple energy sources and/or storage devices which are complement of each other. Thus, higher efficiency can be achieved by taking the advantage of each individual energy source and/or device while overcoming their limitations. In this chapter the comparative analysis of the system having Fuel Cell (FC) energy system with swarm optimizing power electronic converter and proposed Metaheuristic M-PSO Power Stabilizing Controlled converter is done. The output from the system is then studied with the proposed controller with another system having solar/wind/ fuel cell energy resources in a hybrid form and the inverter is controlled by self-designed metaheuristic approach for the inverter control for enhancing all the output parameters as compared to the previous system

The chapter has discussed output from the hybrid system using stabilizer in the following mentioned cases:

CASE 1: FC system with swarm optimizing power electronic converter in grid connected mode

CASE 2: FC system with Metaheuristic M-PSO Power Stabilizing Controlled converter in grid connected mode

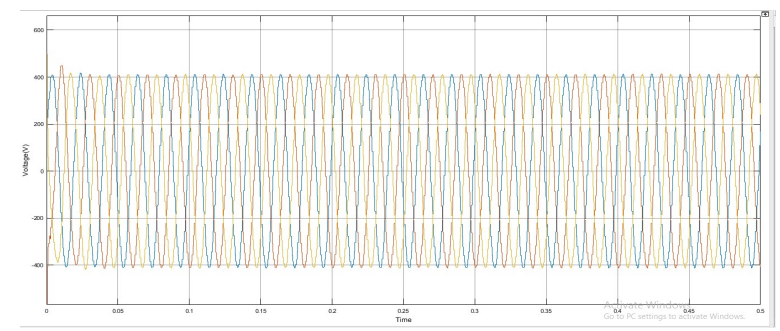

Figure 7: Voltage in the load line in system with swarm optimizing power electronic converter 


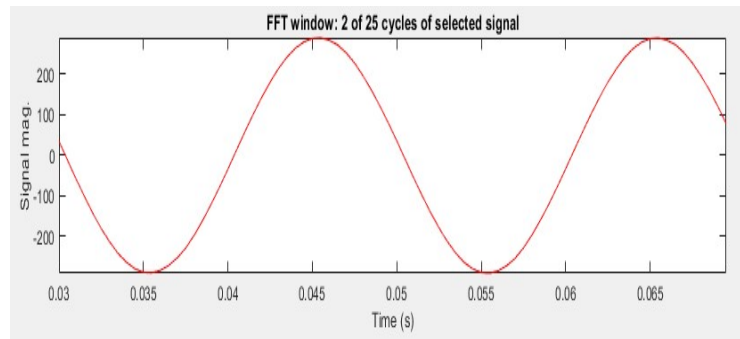

Figure 8: FFT analysis of voltage in load line in FC system

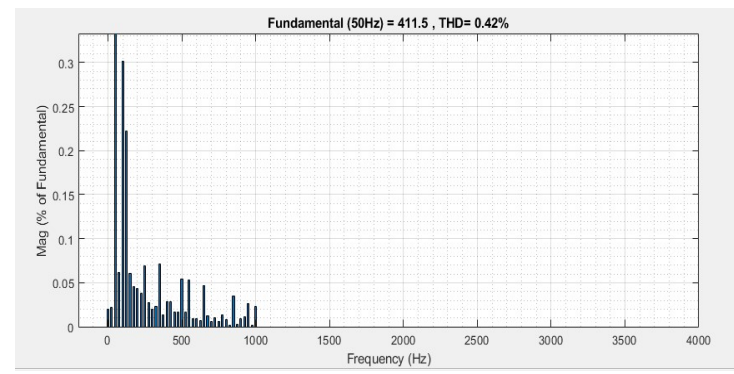

Figure 9: THD \% of voltage in load line in FC system

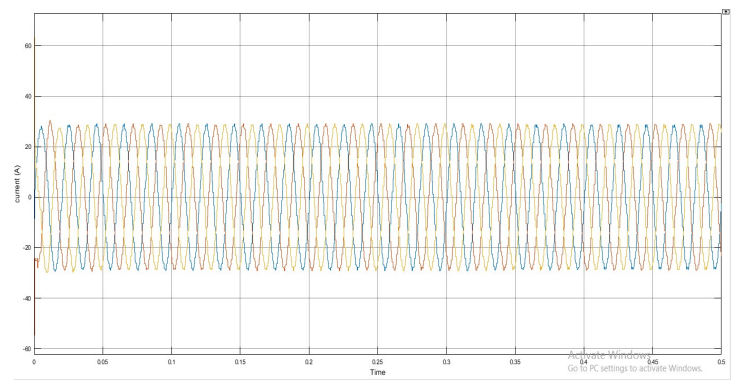

Figure 10: current in the load line in system with swarm optimizing power electronic converter

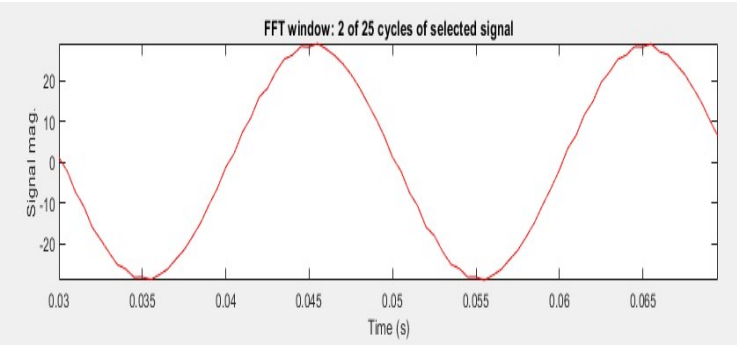

Figure 11: FFT analysis of current in load line in FC system

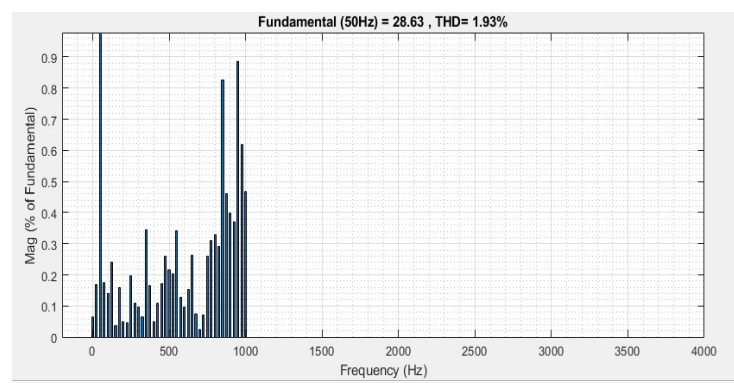

Figure 12: THD \% of current in load line in FC system 


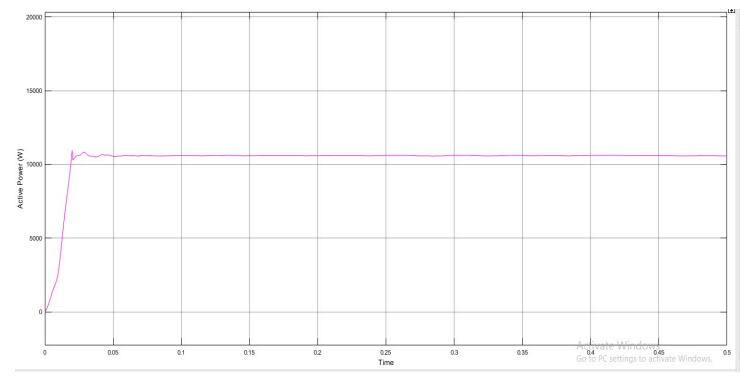

Figure 13: Active Power in the load line in system with swarm optimizing power electronic converter

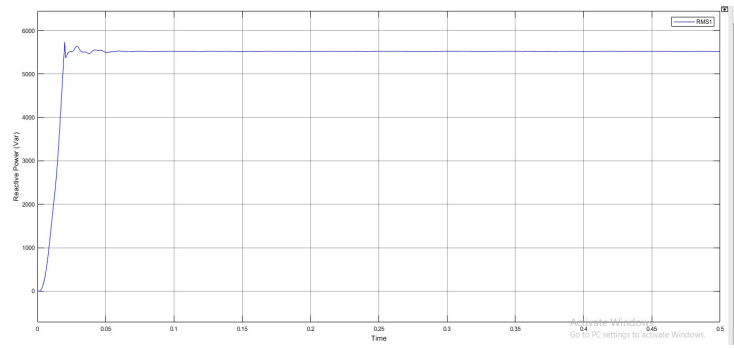

Figure 14: Reactive Power in the load line in system with swarm optimizing power electronic converter

The system voltage has been found to be 410 volts. The current output available at the load terminal after basic voltage regulation based control was found to 29 amperes. On finding the active and reactive power outputs available from the converter that has to be fed to load in this case the results had shown approximately 10570 Watts output and approximately 5517 VAR output for reactive loads. The power factor being calculated as 0.888

CASE 2: FC system with Metaheuristic M-PSO Power Stabilizing Controlled converter in grid connected mode

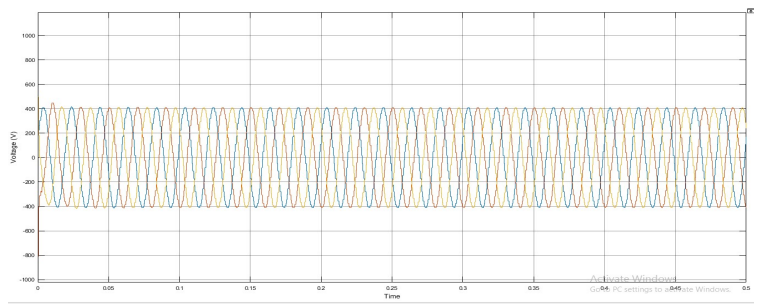

Figure 15: Voltage output in FC system with Metaheuristic M-PSO Power Stabilizing Control

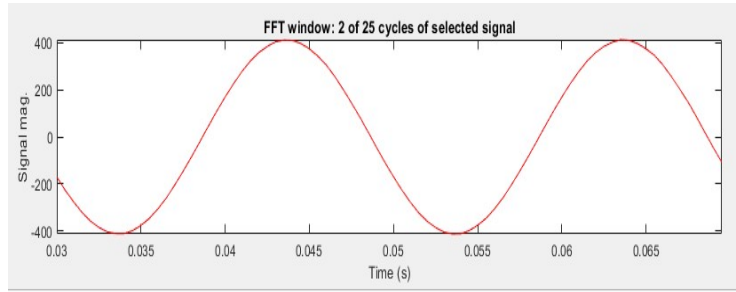

Figure 16: FFT Analysis of Voltage output in FC system with Metaheuristic M-PSO Power Stabilizing Control 


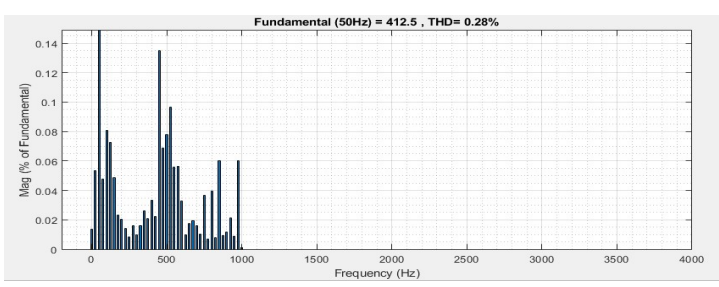

Figure 17: THD\% in Voltage output in FC system with Metaheuristic M-PSO Power Stabilizing Control

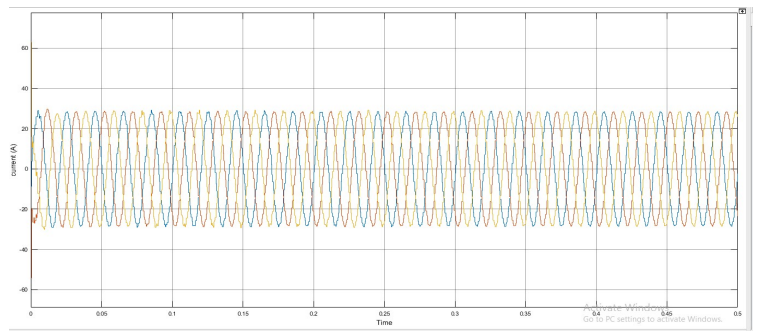

Figure 18: Current output in FC system with Metaheuristic M-PSO Power Stabilizing Control

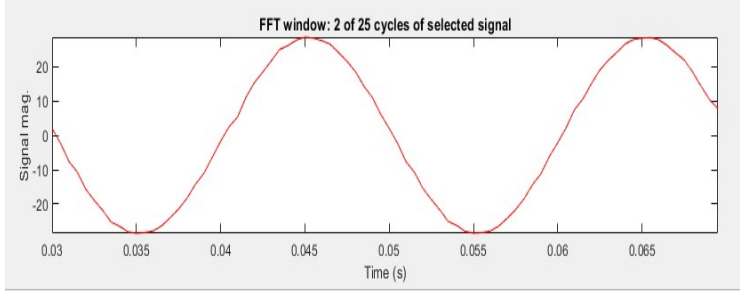

Figure 19: FFT Analysis of Current output in FC system with Metaheuristic M-PSO Power Stabilizing Control

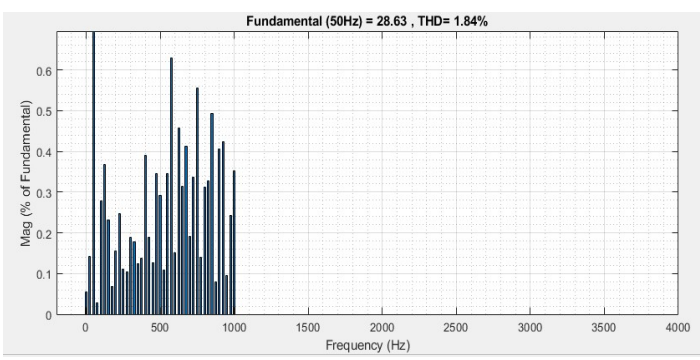

Figure 20: THD\% in Current output in FC system with Metaheuristic M-PSO Power Stabilizing Control

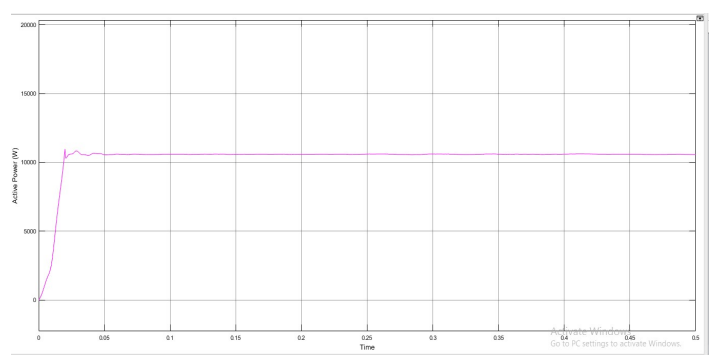

Figure 21: Active Power output in FC system with Metaheuristic M-PSO Power Stabilizing Control 


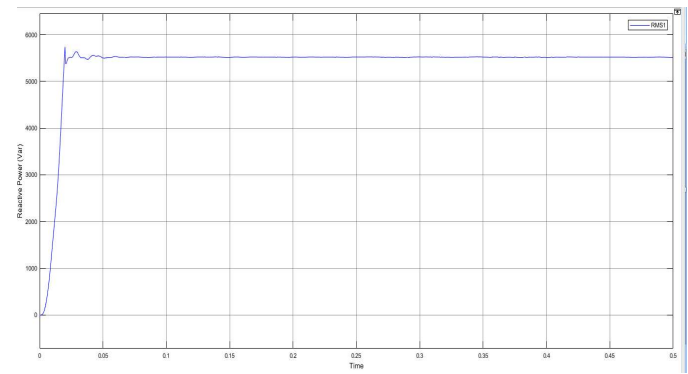

Figure 22: Reactive Power output in FC system with Metaheuristic M-PSO Power Stabilizing Control

The system voltage has been found to be 410 volts. The current output available at the load terminal after basic voltage regulation based control was found to be almost 29 amperes. On finding the active and reactive power outputs available from the converter that has to be fed to load in this case the results had shown approximately $10620 \mathrm{Watts}$ output and approximately 5603 VAR output for reactive loads. The power factor being calculated as 0.893 .

\section{A. Validation}

The graph below is determined to draw the effective characteristics of the designed Metaheuristic M-PSO Power Stabilizing Control for the converter. The comparison has been drawn on the basis of total harmonic distortion (THD\%) in voltage and current waveforms, power output and power factor correction.

Table 3: Comparative analysis of proposed controller

\begin{tabular}{|l|c|c|}
\hline \multicolumn{1}{|c|}{$\begin{array}{c}\text { Electrical } \\
\text { Parameters }\end{array}$} & $\begin{array}{c}\text { system with } \\
\text { swarm } \\
\text { optimizing } \\
\text { power } \\
\text { electronic } \\
\text { converter }\end{array}$ & $\begin{array}{c}\text { FC system } \\
\text { with } \\
\text { Metaheuristic } \\
\text { M-PSO Power } \\
\text { Stabilizing } \\
\text { Control }\end{array}$ \\
\hline $\begin{array}{l}\text { Active power } \\
\text { (Watts) }\end{array}$ & 10570 & 10620 \\
\hline $\begin{array}{l}\text { Reactive power } \\
\text { (VAR) }\end{array}$ & 5517 & 5603 \\
\hline $\begin{array}{l}\text { Power Factor } \\
\text { Calculation }\end{array}$ & 0.888 & 0.893 \\
\hline $\begin{array}{l}\text { THD\% in } \\
\text { voltage }\end{array}$ & 0.42 & 0.28 \\
\hline $\begin{array}{l}\text { THD\% in } \\
\text { current }\end{array}$ & 1.93 & 1.84 \\
\hline
\end{tabular}

The power electronic converter in the fuel cell system was driven by the swarm optimization control and proposed Metaheuristic M-PSO Power Stabilizing Control for conversion from DC to AC outputs. The system performance depicts a considerable enhancement in the power factor and power outcomes of the fuel cell system. The distortion level in the voltage and output from the fuel cell system having swarm optimizing power electronic converter was $0.42 \%$ and $1.93 \%$ respectively that was reduced in fuel cell system with Metaheuristic M-PSO Power Stabilizing Control to $1.84 \%$ and $0.28 \%$ respectively.

CASE 3: Proposed controller analysis with solar Cell Integration in FC system with Metaheuristic M-PSO Power Stabilizing Control

The proposed controller was further subjected to load switching conditions while hybridizing the fuel cell system with solar PV system. Since the output from the solar and fuel cell systems are both DC waveforms the implementation of 
an intermediate converter was eliminated. The Metaheuristic algorithm comprising the variations in irradiation levels as well as temperature rage was developed and optimization of the load side AC parameters was focused.

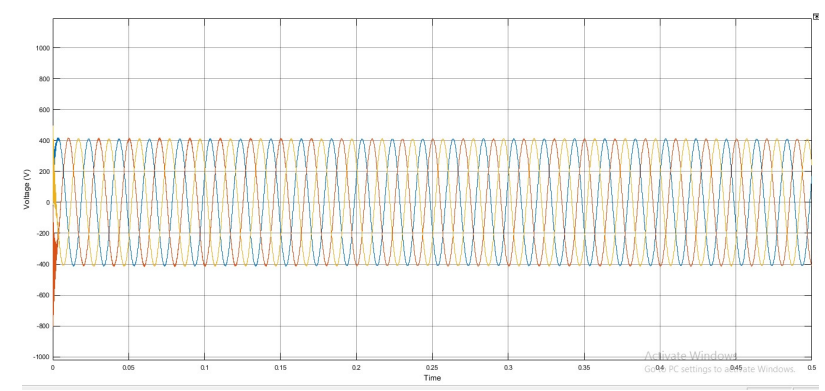

Figure 23: Voltage output in FC/PV system with Metaheuristic M-PSO Power Stabilizing Control

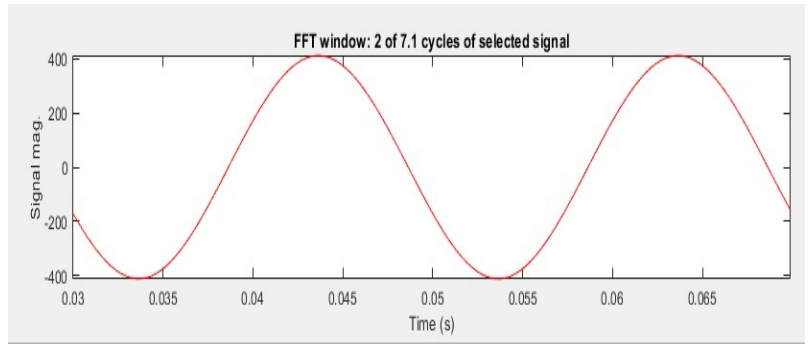

Figure 24: FFT Analysis of Voltage output in FC/PV system with Metaheuristic M-PSO Power Stabilizing Control

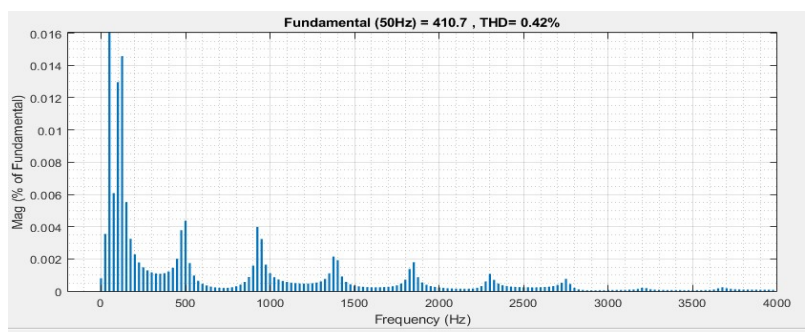

Figure 25: THD\% in Voltage output in FC/PV system with Metaheuristic M-PSO Power Stabilizing Control

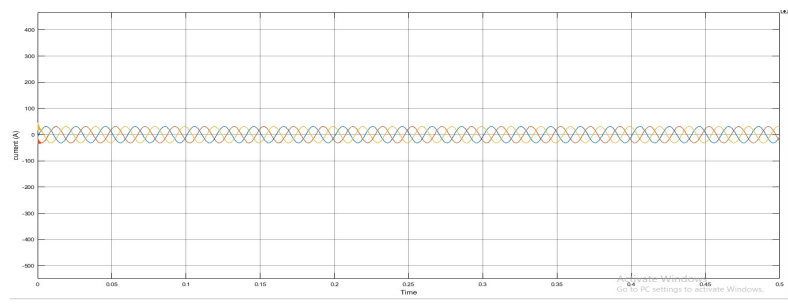

Figure 26: Current output in FC/PV system with Metaheuristic M-PSO Power Stabilizing Control

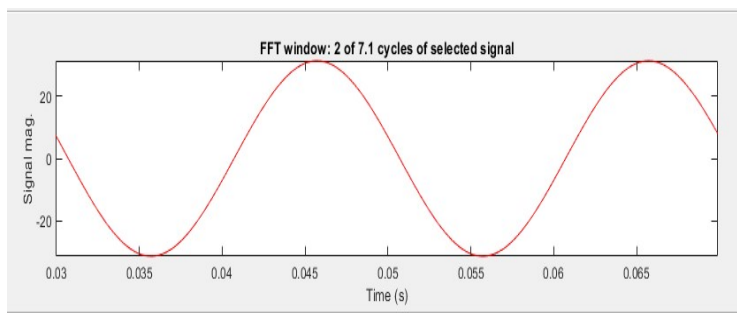

Figure 27: FFT analysis in Current output in FC/PV system with Metaheuristic M-PSO Power Stabilizing Control 


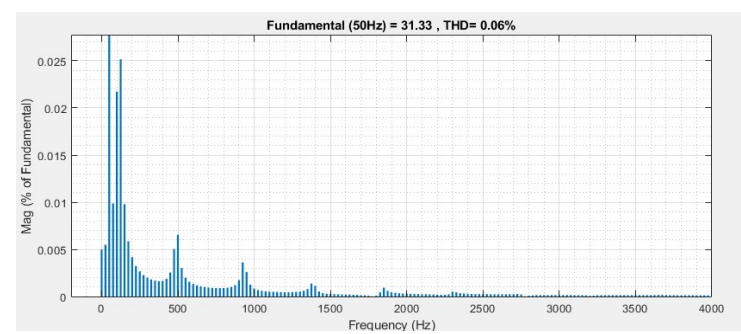

Figure 28: THD\% in Current output in FC/PV system with Metaheuristic M-PSO Power Stabilizing Control

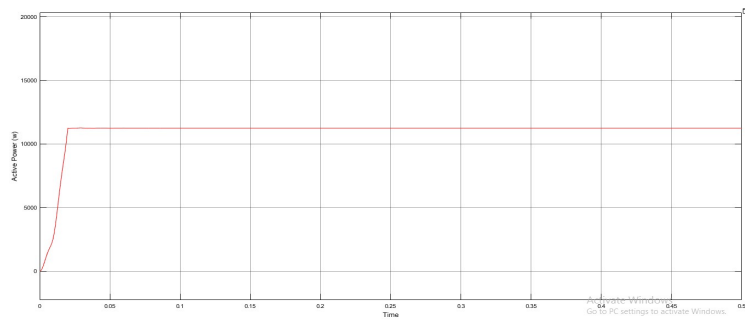

Figure 29: Active Power output in FC/PV system with Metaheuristic M-PSO Power Stabilizing Control

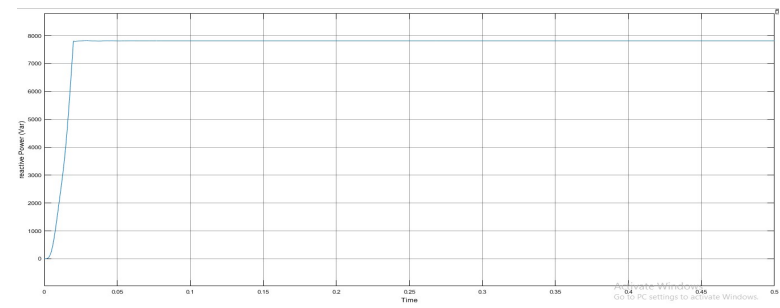

Figure 30: Reactive power output in FC/PV system with Metaheuristic M-PSO Power Stabilizing Control

The system voltage has been found to be 410 volts. The current output available at the load terminal after basic voltage regulation based control was found to be almost 31 amperes. On finding the active and reactive power outputs available from the converter that has to be fed to load in this case the results had shown approximately 11240 Watts output and approximately 7816 VAR output for reactive loads.

CASE 4: Proposed controller analysis with hybrid solar PV and Wind Integration in FC system with Metaheuristic M-PSO Power Stabilizing Control

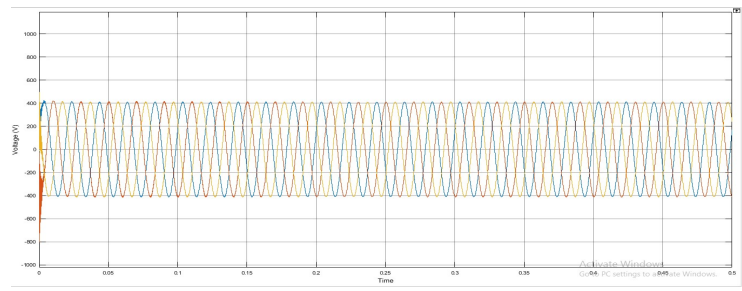

Figure 31: Voltage output in FC/PV/Wind system with Metaheuristic M-PSO Power Stabilizing Control 


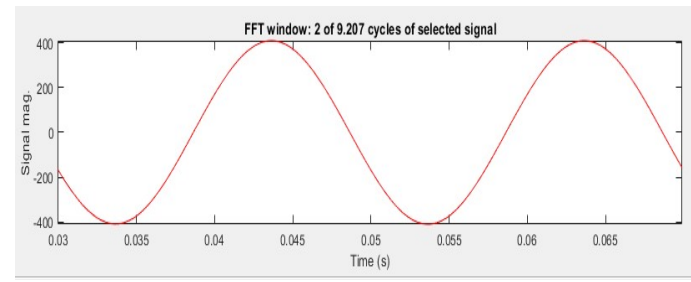

Figure 32: FFT analysis of Voltage output in FC/PV/Wind system with Metaheuristic M-PSO Power Stabilizing Control

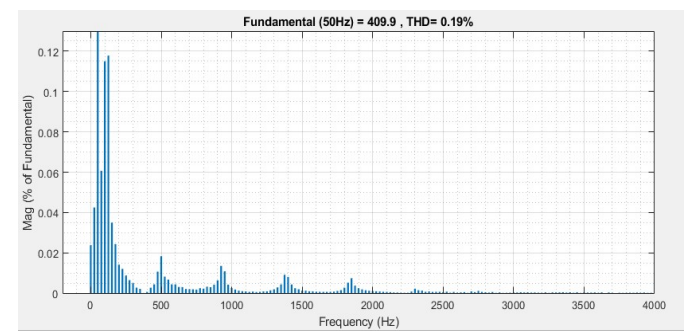

Figure 33: THD\% in Voltage output in FC/PV/Wind system with Metaheuristic M-PSO Power Stabilizing Control

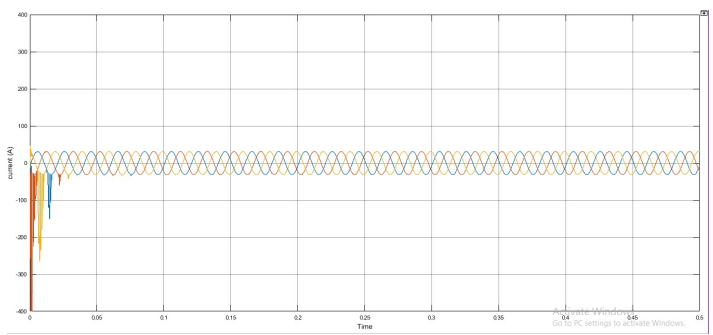

Figure 34: Current output in FC/PV/Wind system with Metaheuristic M-PSO Power Stabilizing Control

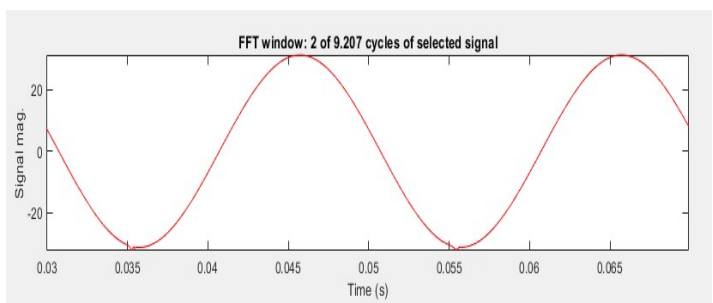

Figure 35: FFT analysis of Current output in FC/PV/Wind system with Metaheuristic M-PSO Power Stabilizing Control

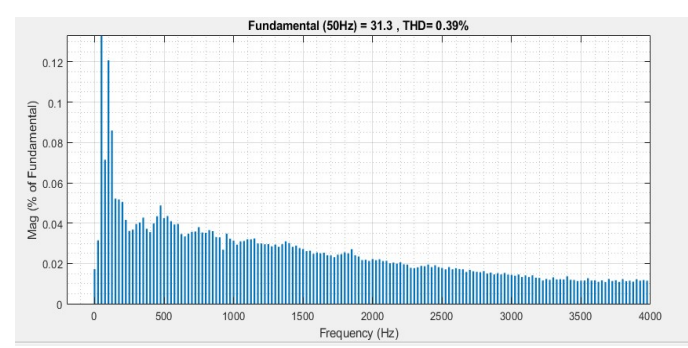

Figure 36: THD\% in Current output in FC/PV/Wind system with Metaheuristic M-PSO Power Stabilizing Control 


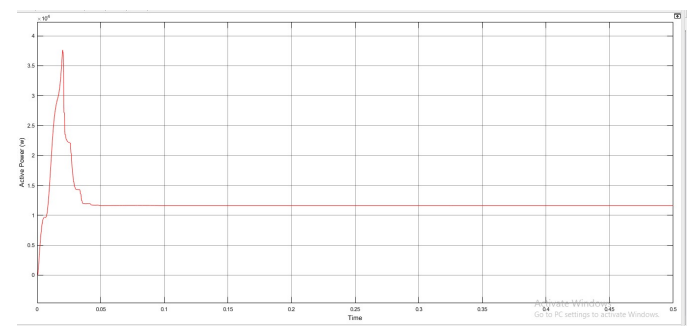

Figure 37: Active Power output in FC/PV/Wind system with Metaheuristic M-PSO Power Stabilizing Control

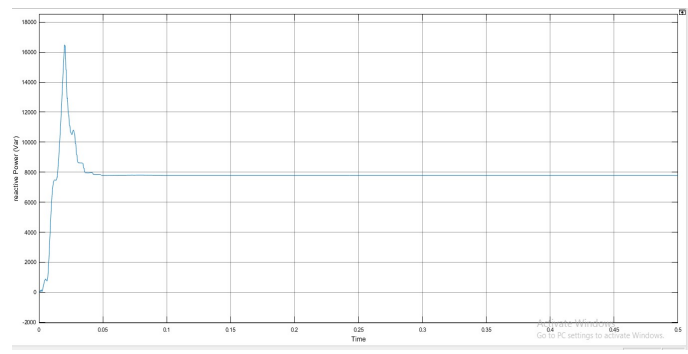

Figure 38: Reactive Power output in FC/PV/Wind system with Metaheuristic M-PSO Power Stabilizing Control

The system voltage has been found to be 410 volts. The current output available at the load terminal after basic voltage regulation based control was found to be almost 31.2 amperes. On finding the active and reactive power outputs available from the converter that has to be fed to load in this case the results had shown approximately $11610 \mathrm{Watts}$ output and approximately 7869 VAR output for reactive loads.

Table 4: Outcome parameters from the renewable energy systems using proposed Metaheuristic M-PSO Power

\section{Stabilizing Control}

\begin{tabular}{|l|c|c|}
\hline \multicolumn{1}{|c|}{$\begin{array}{c}\text { Electrical } \\
\text { Parameters }\end{array}$} & $\begin{array}{c}\text { System } \\
\text { With } \\
\text { FC/Solar } \\
\text { PV System }\end{array}$ & $\begin{array}{c}\text { System With } \\
\text { FC/PV/Wind } \\
\text { System }\end{array}$ \\
\hline $\begin{array}{l}\text { Active power } \\
\text { (Watts) }\end{array}$ & 11240 & 11610 \\
\hline $\begin{array}{l}\text { Reactive power } \\
\text { (VAR) }\end{array}$ & 7816 & 7869 \\
\hline $\begin{array}{l}\text { Power Factor } \\
\text { Calculation in }\end{array}$ & 0.884 & 0.913 \\
\hline $\begin{array}{l}\text { THD\% in } \\
\text { voltage }\end{array}$ & 0.06 & 0.19 \\
\hline $\begin{array}{l}\text { THD\% } \\
\text { current }\end{array}$ & 0.39 \\
\hline
\end{tabular}

\section{CONCLUSIONS}

Renewable energy sources, also called unconventional energies, are continually replenished by natural processes. Hybrid systems are the right solution for clean energy production. Hybridization of solar and wind power sources provides a realistic form of electricity production. Here, a fuel cell system with a converter topology is proposed which makes use of proposed Metaheuristic M-PSO Power Stabilizing Control approach for quality enhancement controller for attaining quality control through inverter. The operational optimization and power-electronics based voltage-power control was developed, and the functioning was demonstrated through simulation. 
Power electronics is a key enabling technology in connecting all energy resources to the dc bus. Their control can functionally enhance the output parameters of the hybrid system. The inverter controller was designed keeping in mind the various parameters of the power system and their respective improvement. The following main conclusions were drawn from the work.

- The designed control was first analyzed for harmonic level distortion in the voltage and current output waveforms at the starting. It was found that the proposed approach has reduced the distortion in voltage as well as current waveform.

- Further the control was analyzed for integrated solar rand then hybrid solar/wind energy system. The electrical parameters were studied and it was found to be more effective using proposed Metaheuristic M-PSO Power Stabilizing Controlled than swarm optimizing control alone.

- The system active power has enhanced from the 10570Watts to 10620Var reducing the internal losses in the converter and enhancing the power factor of the system.

- The simulation was extended to further examination of a hybrid fuel cell and solar PV system. The power quality issues were resolved and power output enhanced

- The final hybrid system with fuel cell integration was studied for the total harmonic distortion in the voltage and current waveform and output active reactive powers. The distortion level in the voltage waveform was found to be $0.19 \%$ and that in the current waveform was $0.35 \%$. The final results showed better performance in terms of quality as compared to the basic swarm optimizing control.

\section{FUTURE SCOPE}

Installing this solar-grid hybrid system will be actually very fruitful because it will reduce the grid dependency. On the other hand, this system promotes green energy which is very important because all the energy sources are depleting day by day. So, people must look for new renewable sources and solar power is definitely one of the best choices in this purpose. In future work an adaptive neural network based control for improved power quality 3 phase grid integrated with nonlinear and linear loads will be designed for this system having three sources in the form of solar/wind/fuel cell based hybrid system. The expected control scheme regulates the system voltage and improves the power quality in a very effective manner.

\section{REFERENCES}

1. F. Paterakis ; C.C. Marouchos "Comparison of a PWM inverter and a multilevel inverter using the switching function analysis for harmonic content and efficiency" 10.1109/UPEC.2017.8231896

2. Himadry Shekhar Das ; Chee Wei Tan "Modeling and simulation of stand-alone fuel cell system for distributed generation application" 10.1109/CEEICT.2016.7873043

3. Alireza Askarzadeh "Distribution generation by photovoltaic and diesel generator systems: Energy management and size optimization by a new approach for a stand-alone application" Volume 122, 1 March 2017, Pages 542-551

4. Fabrizio Sossan "Equivalent electricity storage capacity of domestic thermostatically controlled loads" Volume 122, 1 March 2017, Pages 767-778

5. AliDaşdemir, MustafaErtürk "Effects of air gap on insulation thickness and life cycle costs for different pipe diameters in pipeline" Volume 122, 1 March 2017, Pages 492-504 
6. HuifengZhang, DongYue "Gradient decent based multi-objective cultural differential evolution for short-term hydrothermal optimal scheduling of economic emission with integrating wind power and photovoltaic power" Volume 122, 1 March 2017, Pages 748-766

7. Amina Benabda, Mounia SamiraKelaiaia "Boost chopper MPP assessment based on solar irradiance and predictive duty cycle applied to a PV system” Volume 42, Issue 30, 27 July 2017, Pages 19403-19410

8. J.I.San Martin, I.Zamora "Influence of the rated power in the performance of different proton exchange membrane (PEM) fuel cells" Volume 35, Issue 5, May 2010, Pages 1898-1907

9. N.Djilali “Computational modelling of polymer electrolyte membrane (PEM) fuel cells: Challenges and opportunities” Volume 32, Issue 4, April 2007, Pages 269-280

10. Mohamed I.Mosaad, FawzanSalem "LFC based adaptive PID controller using ANN and ANFIS techniques" Volume 1, Issue 3, December 2014, Pages 212-222 

